\title{
Cognitive dysfunction in adults with Type 1 (insulin-dependent) diabetes mellitus of long duration: effects of recurrent hypoglycaemia and other chronic complications
}

\author{
C.M. Ryan ${ }^{1}$, T.M.Williams ${ }^{1}$, D. N.Finegold ${ }^{2}$ and T.J. Orchard ${ }^{3}$ \\ ${ }^{1}$ Department of Psychiatry, University of Pittsburgh, School of Medicine, Pittsburgh, Pennsylvania, USA \\ ${ }^{2}$ Department of Pediatrics, University of Pittsburgh, School of Medicine, Pittsburgh, Pennsylvania, USA \\ ${ }^{3}$ Graduate School of Public Health, University of Pittsburgh School of Medicine, Pittsburgh, Pennsylvania, USA
}

\begin{abstract}
Summary. To examine the long-term effects of recurrent severe hypoglycaemia and other biomedical complications on mental efficiency, a battery of cognitive tests was administered to 142 Type 1 (insulin-dependent) diabetic adult patients (age $33.5 \pm 5.6$ years; mean $\pm \mathrm{SD}$ ) and 100 demographically similar non-diabetic control subjects. All diabetic subjects had been diagnosed before the age of 17 years. Diabetic subjects with one or more complications (distal symmetrical polyneuropathy; advanced background or proliferative retinopathy; overt nephropathy; one or more episodes of severe hypoglycaemia) performed significantly $(p<0.001)$ more poorly than non-diabetic control subjects on tests requiring sustained attention, rapid analysis of visuospatial detail, and hand eye co-ordination. Regression
\end{abstract}

analyses indicated that the best biomedical predictor of cognitive test performance was a diagnosis of polyneuropathy. Although severe recurrent hypoglycaemia was not associated with performance on any test, the neuropathy $\times$ recurrent hypoglycaemia interaction term was significant. These results suggest that in adults with Type 1 diabetes of long duration, recurrent hypoglycaemia does not appear to influence cognitive performance directly, but may interact with neuropathy to exaggerate or otherwise magnify the extent of neurobehavioural dysfunction.

Key words: Cognitive impairment, hypoglycaemia, hyperglycaemia, adults.
A single episode of moderate hypoglycaemia can readily produce a transient disruption in cognitive functioning. Studies using the insulin-glucose clamp technique have repeatedly demonstrated that when plasma glucose levels are experimentally reduced below $2.8 \mathrm{mmol} / \mathrm{l}$, both diabetic [1-4] and non-diabetic [2, 5-8] subjects often show a marked decline in mental efficiency. Hypoglycaemic-induced neurobehavioural deficits occur most frequently on tasks requiring sustained attention [4,7], rapid decision making $[1,2,7,8]$, analysis of complex visual stimuli [5, 7], "mental flexibility" [3--5, 7], memory for recently learned information $[3,7]$, and hand eye co-ordination $[4,6,7]$.

Cognitive changes that accompany a single episode of experimentally-induced hypoglycaemia are usually considered to be innocuous because neurobehavioural test performance returns to pre-hypoglycaemic baseline levels following restoration of the euglycaemic state. Nevertheless, each episode is necessarily associated with a series of changes in cerebral metabolism [9], including excessive release of excitotoxins such as glutamate [10]. Although the excitotoxic hypothesis of neuronal necrosis is based upon animal studies in which a single episode of very severe hypoglycaemia is maintained for at least $30 \mathrm{~min}$ [11], it is not inconceivable that repeated episodes of moderate hypoglycaemia would, over time, have a cumulative effect that leads to significant neuronal damage in humans. If so, one would expect to find evidence of impairment on a wide range of neurobehavioural measures.

Results from two recent cross-sectional studies are consistent with that prediction. Both Wredling and co-workers [12] and Langan and colleagues [13] found that diabetic adults who had recurrent episodes of severe hypoglycaemia performed worse on cognitive tests than adults with no history of severe hypoglycaemia. On the other hand, Reichard et al. [14] failed to find a relationship between hypoglycaemia and mental efficiency when they examined 5-year follow-up data from a longitudinal study comparing intensive insulin therapy with standard treatment. Despite a three-fold increase in the number of episodes of severe hypoglycaemia, subjects in the intensive insulin treatment group did not differ from standard treatment subjects. Because the interpretation of this negative study has been questioned by other investigators [15], the relationship between recurrent severe hypoglycaemia and cognitive functioning remains controversial [16]. 
Table 1. Demographic characteristics of Type 1 diabetic and nondiabetic subjects

\begin{tabular}{lcccl}
\hline & $\begin{array}{l}\text { Non- } \\
\text { diabetic } \\
\text { subjects }\end{array}$ & $\begin{array}{l}\text { All diabetic } \\
\text { subjects }\end{array}$ & $\begin{array}{l}\text { No compli- } \\
\text { cations }\end{array}$ & $\begin{array}{l}\text { One or } \\
\text { more com- } \\
\text { plications }\end{array}$ \\
\hline $\begin{array}{l}\text { Age (years) } \\
\text { Years of } \\
\text { education }\end{array}$ & $34.1 \pm 6.7$ & $33.5 \pm 5.6$ & $30.7 \pm 5.6$ & $34.4 \pm 5.4$ \\
$\begin{array}{l}\text { Hollingshead } \\
\text { SES }\end{array}$ & $37.1 \pm 11.7$ & $39.1 \pm 12.3$ & $40.9 \pm 13.9$ & $38.5 \pm 11.9$ \\
$\begin{array}{l}\text { WAIS-R } \\
\text { Verbal IQ }\end{array}$ & $101.9 \pm 9.7$ & $98.6 \pm 10.7$ & $96.6 \pm 12.0$ & $99.0 \pm 10.3$ \\
$\begin{array}{l}\text { Proportion of } \\
\text { males (\%) }\end{array}$ & 47 & 51 & 55 & 49 \\
$\begin{array}{l}\text { Proportion of } \\
\text { Blacks }(\%)\end{array}$ & 5 & 1 & 3 & 14.3 \\
\hline
\end{tabular}

Values are means \pm SD. SES, Socioeconomic status; WAIS-R, Wechsler Adult Intelligence Scale, revised

Table 2. Biomedical characteristics of Type 1 diabetic subjects

\begin{tabular}{|c|c|c|c|}
\hline & $\begin{array}{l}\text { All diabetic } \\
\text { subjects }\end{array}$ & $\begin{array}{l}\text { No complica- } \\
\text { tions }\end{array}$ & $\begin{array}{l}\text { One or more } \\
\text { complications }\end{array}$ \\
\hline$n$ & 142 & 29 & 113 \\
\hline Age (years) & $33.5 \pm 5.6$ & $30.7 \pm 5.6$ & $34.3 \pm 5.4^{b}$ \\
\hline Age at onset (years) & $8.7 \pm 4.2$ & $10.2 \pm 3.4$ & $8.3 \pm 4.3^{a}$ \\
\hline $\begin{array}{l}\text { Duration of diabetes } \\
\text { (years) }\end{array}$ & $24.8 \pm 6.1$ & $20.5 \pm 5.8$ & $25.9 \pm 5.6^{\mathrm{c}}$ \\
\hline $\mathrm{HbA}_{1}(\%)$ & $10.6 \pm 1.8$ & $10.7 \pm 1.9$ & $10.6 \pm 1.7$ \\
\hline $\begin{array}{l}\text { Blood glucose at testing } \\
(\mathrm{mmol} / \mathrm{l})\end{array}$ & $11.1 \pm 5.4$ & $11.8 \pm 5.1$ & $10.9 \pm 5.6$ \\
\hline \multicolumn{4}{|l|}{$\begin{array}{l}\text { Clinical neuropathy } \\
\text { score }(\%)\end{array}$} \\
\hline None or possible & 59 & 100 & $49^{c}$ \\
\hline Definite & 41 & 0 & 52 \\
\hline $\begin{array}{r}\text { Retinopathy score }(\%) \\
\text { None or background }\end{array}$ & 39 & 100 & $23^{c}$ \\
\hline $\begin{array}{l}\text { Advanced } \\
\text { background }\end{array}$ & 20 & 0 & 25 \\
\hline Proliferative & 41 & 0 & 51 \\
\hline \multicolumn{4}{|l|}{$\begin{array}{l}\text { Severe hypoglycaemia } \\
(\%)\end{array}$} \\
\hline No & 66 & 100 & $57^{\mathrm{c}}$ \\
\hline Yes & 34 & 0 & 43 \\
\hline
\end{tabular}

Age, duration of diabetes, age at onset, and $\mathrm{HbA}_{1}$ values are given as mean $\pm \mathrm{SD} .{ }^{a} p<0.05 ;{ }^{b} p<0.01 ;{ }^{c} p<0.001$ vs subjects with no complications

Our cross-sectional study was undertaken to examine the interactive effects of repeated hypoglycaemia and other diabetic complications on mental efficiency. To that end, cognitive tests known to be sensitive to hypoglycaemia were included in the assessment battery. All are identical, or analogous, to those used previously in insulinglucose clamp studies. Furthermore, because of the wellknown relationship between duration of diabetes and development of complications [17], Type 1 diabetic adult patients were recruited from a large cohort of subjects who had developed the disease in childhood. Finally, in order to examine the relationship between diabetes and cognitive functioning, a comparison group of demographically similar non-diabetic control subjects was also evaluated.

\section{Subjects and Methods}

\section{Subjects}

Diabetic subjects were randomly selected from the Pittsburgh Epidemiology of Diabetic Complications (EDC) study population [18]. EDC subjects are drawn from the Children's Hospital of Pittsburgh (CHP) Insulin-Dependent Diabetes Mellitus Registry which is a well-defined childhood onset (less than 17 years old) cohort of Type 1 diabetic individuals who were diagnosed or seen within 1 year of diagnosis at CHP between 1950 and 1980. The CHP Registry is considered to be representative of childhood diabetes in Allegheny County. Non-diabetic subjects were recruited by asking each diabetic subject to name a spouse, sibling, "significant other", or close friend. Approximately two-thirds of the control subjects were unrelated; the remainder were spouses. Written informed consent was obtained from all subjects. The protocol had been reviewed and approved by the University of Pittsburgh Institutional Review Board. All subjects were paid for their participation. This paper describes results from 142 diabetic and 100 non-diabetic subjects, all of whom were between the ages of 18 and 49 years (mean $\pm S D$; $33.8 \pm 6.1$ ). The numbers of males and females in each group were similar. Demographic characteristics are summarized in Table 1. Both groups had completed some college or post-secondary education, and their WAIS-R Verbal IQ scores were in the "average" range. There are no statistically significant between-group differences on any variable.

\section{Biomedical measures}

At the time of cognitive assessment, the ambient blood glucose level of diabetic subjects was measured with an Ames Glucometer (Elkhart, Ind., USA). If the level was less than $4.5 \mathrm{mmol} / \mathrm{l}$, a snack was consumed before testing. EDC staff conducted all other biomedical evaluations, and the technicians administered the cognitive tests without prior knowledge of the EDC results.

Distal symmetric polyneuropathy (DSP) was determined with the Diabetes Control and Complications Trial (DCCT) protocol clinical examination [19]. A dichotomous scale was used. DSP was considered "definitely present" if two of the following three criteria were met and could not be attributed to a non-diabetic cause: (1) symptoms consistent with DSP; (2) decreased or absent tendon reflexes; (3) signs of sensory loss.

Retinopathy was determined with three field (designations 1,2, and 4) stereoscopic fundus photography taken by a Zeiss camera and read by the University of Wisconsin-Madison Fundus Photography Reading Center. Readings were classified into four categories according to the modified Airlie House System [20]: (1) no retinopathy (grade 10 in both eyes); (2) early background (highest grade 20 or 30 in either eye); (3) advanced background (highest grade 40 or 50); (4) proliferative (grade 60 or higher in at least one eye, or a grade less than 60 but with panretinal photocoagulation scars consistent with laser therapy). In our analyses, the "no retinopathy" and "early background" categories were collapsed into a single category because no retinopathy was such a rare event in the complications subgroup $(n=1)$.

Overt nephropathy was defined as (1) presence of renal failure (serum creatinine $>440 \mu \mathrm{mol} / \mathrm{l}$; being placed on dialysis; or postrenal transplant), (2) increased albumin excretion rate 
Table 3. Raw scores (mean \pm SD) from neuropsychological tests and $95 \%$ confidence intervals for non-diabetic and Type 1 diabetic subjects

\begin{tabular}{lcccc}
\hline & $\begin{array}{l}\text { Non-diabetic } \\
\text { controls }\end{array}$ & $\begin{array}{l}\text { All diabetic } \\
\text { subjects }\end{array}$ & $\begin{array}{l}\text { No compli- } \\
\text { cations }\end{array}$ & $\begin{array}{l}\text { One or more } \\
\text { complications }\end{array}$ \\
\hline Digit Vigilance & $363.7 \pm 77.9$ & $400.7 \pm 98.1$ & $378.6 \pm 87.7$ & $406.4 \pm 100.2^{\mathrm{a}}$ \\
time & $348.2-379.2$ & $384.5-417.0$ & $345.2-411.9$ & $387.8-425.1$ \\
Embedded & $7.4 \pm 2.7$ & $9.2 \pm 4.6$ & $7.9 \pm 2.9^{\mathrm{b}}$ & $9.5 \pm 4.9^{\mathrm{a}}$ \\
Figures time & $6.9-7.9$ & $8.5-9.9$ & $6.8-9.0$ & $8.6-10.5$ \\
Trail Making- & $54.3 \pm 18.2$ & $58.3 \pm 22.3$ & $59.9 \pm 24.8$ & $57.8 \pm 21.6$ \\
part B & $50.7-57.9$ & $54.6-61.9$ & $50.4-69.4$ & $53.8-61.9$ \\
Grooved & $64.2 \pm 9.4$ & $76.1 \pm 16.1$ & $66.3 \pm 8.7^{\mathrm{b}}$ & $78.6 \pm 16.6^{\mathrm{a}}$ \\
Pegboard & $62.3-66.0$ & $73.4-78.7$ & $63.0-69.6$ & $75.5-81.7$ \\
Story Forget- & $21.5 \pm 16.3$ & $22.5 \pm 15.1$ & $19.7 \pm 11.8$ & $23.3 \pm 15.9$ \\
ting Score & $18.2-24.7$ & $19.9-25.0$ & $15.2-22.2$ & $20.3-26.2$ \\
\hline
\end{tabular}

High scores reflect poorer performance. Tukey post-hoc contrasts: ${ }^{a} p<0.05$ non-diabetic control subjects vs diabetic subjects with complications; ${ }^{b} p<0.05$ diabetic subjects with one or more complications vs those with no complications

( $>200 \mu \mathrm{g} / \mathrm{min}$ in two of three timed urine samples, or (3) in the absence of urine time collections, a serum creatinine greater than $180 \mu \mathrm{mol} / 1$.

Glycosylated haemoglobin $\left(\mathrm{HbA}_{1}\right)$ values were determined with saline-incubated blood samples and high-performance liquid chromatography (Diamat; Bio-Rad, Hercules, Calif., USA).

Severe hypoglycaemia was ascertained by means of a structured interview. Subjects were asked if they have "ever had an episode of hypoglycaemia so severe that you sought medical help (emergency room; doctor)?" If yes, further questions about loss of consciousness and seizures were asked. Subjects were then asked to estimate the total number of such episodes they had experienced, and were asked to provide details of each. Whenever possible, estimates were corroborated by another family member, and by review of medical records. The resulting frequency distribution from the 48 subjects reporting one or more severe hypoglycaemic events was categorized into septiles, having median values of $1,2,4,10,15,50$, and 150 lifetime hypoglycaemic episodes, respectively. Subsequent regression analyses used categorical septile scores (values 0 for none, and 1-7).

Age at onset was dichotomized into "early" (diagnosis at or before 5 years of age) or "later" (after age 5) based on previous research $[21,22]$.

Diabetic subjects were stratified into two groups: those without complications, and those with one or more complications. Subjects were assigned to the no complications subgroup if they met all of the following four criteria: (1) no DSP; (2) no advanced background or proliferative retinopathy in either eye; (3) no overt nephropathy; and (4) no previous episodes of severe hypoglycaemia. Twenty-nine subjects had no complications; 113 had one or more complications.
Biomedical characteristics are summarized in Table 2 for the entire diabetic group, and for each of the two subgroups.

\section{Cognitive measures}

General intelligence was estimated from the Verbal IQ score derived from the six verbal subtests comprising the WAIS-R [23]. The remaining cognitive tests are identical, or analogous, to tasks used by us in hyperinsulinaemic clamp studies of adults [7].

The Digit Vigilance Test provides a measure of sustained attention. Subjects are presented with two pages of numbers and told to cross out all sixes as quickly as possible. The response measure is total time (in seconds) to complete the task [24].

The Embedded Figures Test provides a measure of visual scanning and rapid decision making. On each of ten trials, subjects see a card with a geometric design (target) in the upper half and four complex patterns in the lower half. Their task is to identify the pattern with the target. The response measure is mean latency to correct identification [25].

The Trail Making Test (part B) yields an estimate of "mental flexibility". Subjects are presented with a page of numbers and letters and are told to draw a line that alternates sequentially between the two $(1-\mathrm{A}-2-\mathrm{B}$, etc. $)$. Total time to complete the task is the response measure [26].

The Grooved Pegboard Test [27] assesses hand eye co-ordination. Subjects are required to place $25 \mathrm{key}$-shaped pegs into a formboard as quickly as possible. The time to complete the task with the dominant hand is the response measure.

The Logical Memory subtest from the Wechsler Memory Scale [28] provides a measure of memory over a brief delay. A short story is read to the subject, who tells it back immediately after hearing it. Thirty minutes later the subject is asked to recall the story again. The response measure is the percent forgotten.

\section{Statistical analysis}

Non-parametric procedures were used to determine the association between severity of hypoglycaemia and severity of other biomedical complications. Analysis of variance techniques were used to compare the cognitive test scores of the non-diabetic controls with the diabetic subjects. To test the hypothesis that only diabetic subjects with one or more complications manifest significant cognitive impairment, a two-step analytic procedure was used. Control subjects were first compared with all diabetic subjects on each of five tests. If the omnibus $F$ for that measure was significant, the Tukey "honestly significant difference" post-hoc procedure was used to compare the three groups. Within the diabetic sample, the association between biomedical variables and cognitive test scores was evaluated with multiple regression procedures. All analyses were run with the SPSS-PC + V3.0 statistical package [29].

Table 4. Results from hierarchical regression analysis of cognitive test scores

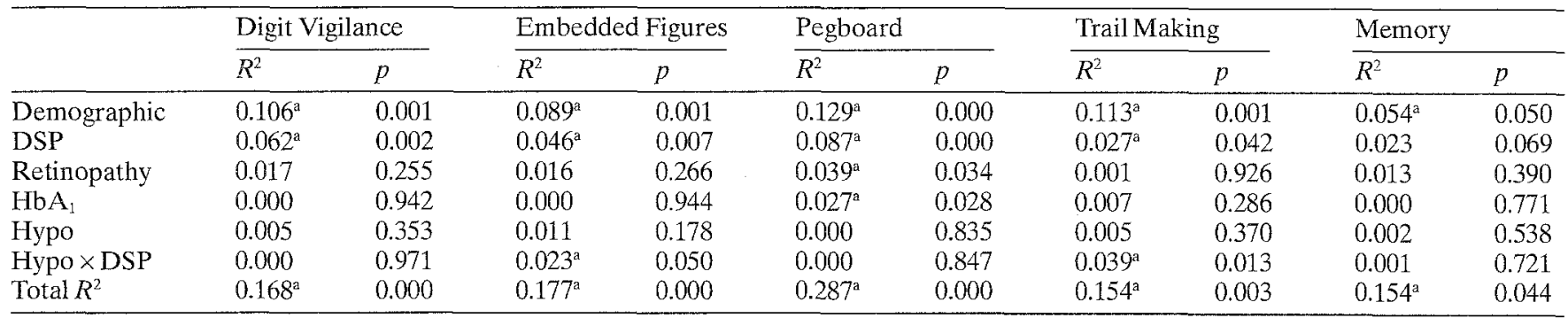

$R^{2}$ indicates total amount of variance attributed to each specific predictor variable; $p$ indicates the probability that this change is greater than $0 .{ }^{a} R^{2}$ values that are statistically significant $(p<0.05)$. Total $R^{2}$ includes only those variables that entered equation. Predictor variables were omitted if they did not account for a statistically significant amount of variance. DSP, Distal symmetrical polyneuropathy; Hypo, hypoglycaemia 


\section{Results}

No relationship was found between number of previous episodes of severe hypoglycemia and degree of neuropathy $\left(X^{2} \quad(d f=14)=14.7 ; p>0.35\right)$, retinopathy $\left(X^{2}\right.$ $(d f=21)=26.2 ; \quad p>0.15)$ or nephropathy $\left(X^{2}\right.$. $(d f=14)=15.0 ; p>0.35)$. Cognitive test scores are summarized in Table 3 . As a group, the 142 diabetic subjects performed significantly worse than non-diabetic control subjects on three of the five tests. On the Digit Vigilance Test, both groups of subjects made similar numbers of omission errors (control subjects: 6.1; diabetic subjects: $5.6 ; F(1,240)<1$ ), but diabetic subjects took significantly longer $(F(1,240)=9.87 ; p<0.002)$ to complete the task than control subjects. Both groups earned identical accuracy scores on the Embedded Figures Test ( 8.6 items; $F<1$ ), but the diabetic subjects required significantly more time $(F(1,240)=11.69 ; p<0.001)$ to identify each target accurately. Very large between-group differences were also evident on the Grooved Pegboard Test $(F(1,240)=44.14 ; p<0.0001)$. Diabetic subjects were approximately $19 \%$ slower than control subjects. They required, on average, an additional $12 \mathrm{~s}$ to insert 25 pegs into the pegboard with their dominant hand. In contrast, there were no statistically reliable differences on the Trail Making Test $(F(1,240)=2.2 ; p=0.14)$ or on the Logical Memory Forgetting score $(F<1 ; \mathrm{NS})$.

In the next series of analyses, Tukey post-hoc comparisons were conducted for those three cognitive measures scores that had initially discriminated between diabetic and non-diabetic subjects. To test the hypothesis that biomedical complications were associated with cognitive dysfunction, data from 29 subjects with no complications were compared with data from 113 having one or more complications. Inspection of Table 2 indicates that those subjects with no complications were significantly younger $(t=3.18 ; p=0.003)$, developed diabetes at a significantly later age $(t=2.5 ; p=0.015)$, and had diabetes for a significantly shorter period of time $(t=4.64 ; p=0.0001)$. Contrasts between non-diabetic control subjects and the no complications subgroup indicated that the two groups performed comparably on all cognitive tests (all $p>0.20$ ). That result did not change when age was co-varied. By contrast, the diabetic subjects with complications were significantly impaired $(p<0.05)$, relative to non-diabetic controls, on the Digit Vigilance Test, the Embedded Figures Test, and on the Grooved Pegboard Test. Diabetic subjects with complications were also more impaired $(p<0.05)$ than those without complications on the Grooved Pegboard and the Embedded Figures Test.

To determine the unique and synergistic contributions of specific biomedical complications to cognitive dysfunction, hierarchical multiple regression techniques were applied to the entire diabetic sample of 142 subjects. For each cognitive test score, an eight-step procedure was employed. Demographic variables (age, years of education, gender) were entered first to control for the possible effects of those variables on cognitive functioning. The presence or absence of DSP was entered on step 2, because previous work had demonstrated that peripheral neuropathy may be associated with brain dysfunction, as indexed by neuropsychological [30], neurophysiological [31], and neuroradiological [31] measures. Level of retinopathy (none or background; advanced background; proliferative) was entered on step 3 . This variable was included because all but one of the cognitive tests have a visual component that could be influenced by visual acuity difficulties. Although DSP and degree of retinopathy are intercorrelated to some extent, the relatively small correlation coefficient $(r=0.39)$ did not meet criteria for multicollinearity [32]. Nephropathy (overt; none or incipient) were entered on step 4 and $\mathrm{HbA}_{1}$ (coded as a continuous variable) was entered on step 5 to determine the relationship between performance and other markers of hyperglycaemia. Severe hypoglycaemia was entered on step 6. This was coded as a categorical variable that ranged from 0 to 7 . Age at onset, coded dichotomously as early (before 5 years of age) or later, was entered on step 7. A series of interaction terms (hypoglycaemia $\times$ DSP; hypoglycaemia $\times$ retinopathy; retinopathy $\times$ DSP) was entered on the last step, to determine if hypoglycaemic episodes served to moderate or exaggerate the effects of other complications on cognitive test scores [33].

Results from the regression analyses are summarized in Table 4. After controlling for demographic variables, a diagnosis of DSP was consistently the best predictor of performance on all measures, except memory (which was not associated with any biomedical predictor). Adding the retinopathy score to the model accounted for a small, but statistically significant, amount of additional variance; this was limited to performance on the Grooved Pegboard Test. Overt nephropathy was not associated with cognitive test scores, whereas $\mathrm{HbA}_{\text {1 }}$ was a weak predictor $\left(R^{2}=0.028\right)$ on only one measure - Grooved Pegboard. Remarkably, previous episodes of hypoglycaemia had no impact on any cognitive test scores. On the other hand, significant interaction effects between hypoglycaemia and DSP were found on both the Trail Making Test, and on the Embedded Figures Test. No other biomedical variables or interaction terms were statistically significant. The total amount of variance (total $R^{2}$ ) accounted for by all of the variables (biomedical; interaction terms; demographic) ranged from 6\% (Memory) to $29 \%$ (Grooved Pegboard).

\section{Discussion}

Previous studies have suggested that cognitive impairment may be a common, but generally unrecognized, complication of Type 1 diabetes [34-39]. Our results are consistent with that view. As a group, adults who developed Type 1 diabetes in childhood or adolescence performed more poorly than age- and education-matched non-diabetic subjects on a variety of cognitive tests. Our results also suggest that the primary predictor of neurobehavioural dysfunction is not having diabetes per se, but having developed clinically significant diabetic complications. We found that adults with no biomedical complications earned scores that were indistinguishable from healthy control subjects. In contrast, those who had one or more complications performed significantly worse than controls and diabetic subjects without complications - especially on tasks that re- 
quired sustained attention, rapid analysis of visuospatial detail, and hand eye co-ordination.

An examination of the relationship between specific complications and cognitive test scores provided no evidence of a direct effect of recurrent hypoglycaemia on performance, despite the fact that previous studies had demonstrated that these particular cognitive tests are sensitive to acute hypoglycaemia. Furthermore, retinopathy was not a potent predictor of performance, even though all of the tests that discriminated diabetic from nondiabetic subjects had a visual component. Of the biomedical variables examined, the best predictor was distal symmetrical polyneuropathy. Diabetic subjects who met criteria for DSP performed worse on all tasks, except memory (which was not influenced by any variable). The relationship between DSP and test scores could not be attributed to peripheral sensory or motor problems, because performance on tasks having no kinesthetic or motoric requirements, like the Embedded Figures Test, was also most strongly associated with DSP score.

Although cognitive performance was not directly influenced by recurrent hypoglycaemia alone, it was influenced by the interaction between recurrent hypoglycaemia and DSP. That is, the hypoglycaemia $\times$ DSP interaction term accounted for a small but statistically significant amount of variance on both the Embedded Figures Test and the Trail Making Test. No other interaction term predicted performance.

Discussions of the aetiology of diabetes-associated cognitive dysfunction have generally emphasized the role of hypoglycaemia, and not hyperglycaemia. Certainly, an acute episode of hypoglycaemia is far more likely to produce a dramatic (albeit transient) deterioration in mental efficiency than is an acute episode of hyperglycaemia $[2,4$, 40]. Moreover, clinical case reports have indicated that a single episode of severe hypoglycaemia may produce a variety of transient or permanent neurological disorders including hemiplegia [41], amnesia [42], and coma [43], while neuropathological studies have demonstrated the presence of hypoglycaemic-associated neuronal necrosis in the cortex, hippocampus, and basal ganglia of humans $[43,44]$ and animals $[45,46]$. This focus on hypoglycaemia has led many clinicians to ignore the possibility that cognitive dysfunction may also be associated with chronic hyperglycaemia. Nevertheless, there is increasing evidence to suggest that chronic hyperglycaemia and its biomedical complications may trigger, or be associated with, significant brain dysfunction.

The most consistent neurobehavioural evidence for a relationship between hyperglycaemia and cognitive impairment comes from studies of elderly Type 2 (non-insulin-dependent) diabetic adult patients. Performance on a wide variety of cognitive tests is correlated with glycosylated haemoglobin levels: the poorer the degree of metabolic control, the greater the level of impairment. This is most apparent on learning and memory tests [34, 47-49], but has also been reported on tests of attention and concept formation [50]. Research with younger Type 1 diabetic adult subjects has produced less consistent results. Some investigators [51] have reported no relationship between neuropsychological test performance and the presence of hyperglycaemic complications like neuropathy, while others, including our group [30], have noted such an association, particularly on psychomotor tasks. On the other hand, neurophysiological [52-55] and neuroimaging studies [31] have demonstrated that diabetic adults with a history of poor metabolic control have clear evidence of brain dysfunction. This has been demonstrated most convincingly by Dejgaard et al. [31], who studied 20 middleaged diabetic adults, all of whom had evidence of peripheral neuropathy. Abnormal brain stem auditory evoked potentials were found in $40 \%$ of these subjects, and abnormal magnetic resonance imaging results (characterized as lesions $2-10 \mathrm{~mm}$ in size) were found in $69 \%$ of the diabetic subjects. Taken together, these studies suggest that chronic hyperglycaemia may be associated with the development of a "central neuropathy".

There is no doubt that a severe episode of hypoglycaemia may result in significant brain dysfunction. By the same token, chronic hyperglycaemia - as indexed by elevated glycosylated haemoglobin values or the presence of complications such as neuropathy, may also result in brain dysfunction. In an earlier discussion of the possible interactive effects of hypo- and hyperglycaemia on microvascular disease, Frier and Hilsted [56] suggested that hypoglycaemia may aggravate the complications of diabetes. Results from the present study are consistent with that view. Although the exact mechanism remains obscure, it appears that hypoglycaemia aggravates the neurobehavioural complications that are associated with longterm diabetes.

Acknowledgements. This work was supported by National Institutes of Health Grants DK-39629 and DK-34818.

\section{References}

1. Holmes CS, Hayford JT, Gonzales JL, Weydert JA (1983) A survey of cognitive functioning at different glucose levels in diabetic persons. Diabetes Care 6: 180-185

2. Herold KC, Polonsky KS, Cohen RM, Levy J, Douglas F (1985) Variable deterioration in cortical function during insulin-induced hypoglycemia. Diabetes 34: 677-685

3. Pramming S, Thorsteinsson B, Theilgaard A, Pinner EM, Binder C (1986) Cognitive function during hypoglycaemia in type $I$ diabetes mellitus. Br Med J 292: 647-650

4. Hoffman RG, Speelman DJ, Hinnen DA, Conley KL, Guthrie RA, Knapp RK (1989) Changes in cortical functioning with acute hypoglycemia and hyperglycemia in type 1 diabetes. Diabetes Care 3: 193-197

5. Widom B, Simonson DC (1990) Glycemic control and neuropsychologic function during hypoglycemia in patients with insulindependent diabetes mellitus. Ann Intern Med 112: 904-912

6. Stevens AB, McKane WR, Bell PM, Bell P, King DJ, Hayes JR (1989) Psychomotor performance and counterregulatory responses during mild hypoglycemia in healthy volunteers. Diabetes Care 12: 12-17

7. Mitrakou A, Ryan C, Veneman T et al. (1991) Hierarchy of glycemia thresholds for counterregulatory hormone secretion, symptoms, and cerebral dysfunction. Amer J Physiol 260: E67E74

8. Kerr D, Macdonald IA, Tattersall RB (1989) Adaptation to mild hypoglycaemia in normal subjects despite sustained increases in counter-regulatory hormones. Diabetologia 32: 249-254

9. Bachelard H (1981) Cerebral metabolism and hypoglycaemia. In: Marks V, Rose FC (eds) Hypoglycaemia, 2 nd edn. Blackwell Scientific Publications, Oxford, London, pp 51-68 
10. Siesjo BK, Bengtsson F (1989) Calcium fluxes, calcium antagonists, and calcium related pathology in brain ischemia, hypoglycemia and spreading depression: a unifying hypothesis. J Cereb Blood Flow Metab 9: 127-140

11. Auer RN, Wieloch T, Olsson Y, Siesjo BK (1984) The distribution of hypoglycemia brain damage. Acta Neuropathol 64: 177191

12. Wredling R, Levander S, Adamson U, Lins PE (1990) Permanent neuropsychological impairment after recurrent episodes of severe hypoglycaemia in man. Diabetologia 33: 152-157

13. Langan SJ, Deary IJ, Hepburn DA, Frier BM (1991) Cumulative cognitive impairment following recurrent severe hypoglycaemia in adult patients with insulin-treated diabetes mellitus. Diabetologia 34: $337-344$

14. Reichard P, Britz A, Rosenquist U (1991) Intensified conventional insulin treatment and neuropsychological impairment. $\mathrm{Br}$ Med J 303: 1439-1442

15. Deary IJ, Frier BM (1992) Intensified conventional insulin treatment and neuropsychological impairment. Br Med J 304: 447 (Letter)

16. Reichard P (1992) Author's reply. Br Med J 304: 447 (Letter)

17. Chase HP, Jackson WE, Hoops SL et al. (1989) Glucose control and the renal and retinal complications of insulin-dependent diabetes. JAMA 261: 1155-1160

18. Orchard TJ, Dorman JS, Maser RE et al. (1990) Prevalence of complications in IDDM by sex and duration: Pittsburgh Epidemiology of Diabetes Complications Study II. Diabetes 39: 1116-1124

19. DCCT Research Group (1988) Factors in development of diabetic neuropathy: baseline analysis of neuropathy in feasibility phase of Diabetes Control and Complications Trial (DCCT). Diabetes 37: 476-481

20. Early Treatment of Diabetic Retinopathy Study Coordinating Center (1989) Manual of Operations. University of Maryland, Baltimore

21. Ryan C, Vega A, Drash A (1985) Cognitive deficits in adolescents who developed diabetes early in life. Pediatr 75:921-927

22. Ack M, Miller I, Weil W (1961) Intelligence of children with diabetes mellitus. Pediatr 28: 764-770

23. Wechsler D (1981) Manual for Wechsler adult intelligence scalerevised. Psychological Corp., New York

24. Lewis R, Rennick P (1979) Manual for the repeatable cognitiveperceptual-motor battery. Axon, Grosse Pointe Park, Michigan

25. Ryan C, Morrow L, Bromet E, Parkinson D (1987) Assessment of neuropsychological dysfunction in the workplace: normative data from the Pittsburgh occupational exposures test battery. $\mathrm{J}$ Clin Exper Neuropsychol 9: 665-679

26. Boll T (1981) The Halstead-Reitan neuropsychological battery. In: Filskov S, Boll T (eds) Handbook of clinical neuropsychology. Wiley, New York, pp 577-607

27. Rourke B, Yanni D, MadDonald G, Young G (1973) Neuropsychological significance of lateralized deficits on the grooved pegboard test for older children with learning disabilities. J Consult Clin Psychol 41: 128-134

28. Wechsler D (1945) A standardized memory scale for clinical use. J Psychol 19:87-95

29. SPSS Inc (1988) SPSS/PC + 3.0 for the IBM PC. SPSS, Chicago

30. Ryan CM, Williams TM, Orchard TJ, Finegold DN (1992) Psychomotor slowing is associated with distal symmetrical polyneuropathy in adults with diabetes mellitus. Diabetes 41: 107 113

31. Dejgaard A, Gade A, Larsson H, Balle V, Parving A, Parving H (1991) Evidence for diabetic encephalopathy. Diabetic Med 8: 162-167

32. Tabachnick BG, Fidell LS (1989) Using multivariate statistics 2 nd edn. Harper Collins Publishers, New York

33. Baron RM, Kenny DA (1986) The moderator-mediator variable distinction in social psychological research: conceptual, strategic, and statistical considerations. J Pers Soc Psychol 51: 1173-1182

34. Ryan C (1988) Neurobehavioral complications of type 1 diabetes: examination of possible risk factors. Diabetes Care 11:86-93
35. Meuter F, Thomas W, Gruneklee D, Gries F, Lohmann R (1980) Psychometric evaluation of performance in diabetes mellitus. Horm Metab Res 9 [Suppl]: 9-17

36. Franceschi M, Cecchetto R, Minicucci F, Smizne S, Baio G, Canal N (1984) Cognitive processes in insulin-dependent diabetes. Diabetes Care 7: 228-231

37. Skenazy J, Bigler E (1984) Neuropsychological findings in diabetes mellitus. J Clin Psychol 40: 246-258

38. Bale R (1973) Brain damage in diabetes mellitus. Br J Psych 122: 337-341

39. Rennick P, Wilder R, Sargent J, Ashley B (1968) Retinopathy as an indicator of cognitive-perceptual-motor impairment in diabetic adults [Summary]. Proceedings of the 76 th Annual Convention of the American Psychological Association, pp 473-474

40. Draelos M, Weinger K, Fritz S, Jacobson A (1992) Cognitive function and long-term glycemic control. Diabetes [Suppl 1] 42: $13 \mathrm{~A}$ (Abstract)

41. Wallis WE, Donaldson I, Scott RS, Wilson J (1985) Hypoglycemia masquerading as cerebrovascular disease (hypoglycemic hemiplegia). Ann Neurol 18: 510-512

42. Chalmers J, Risk MTA, Kean DM et al. (1991) Severe amnesia after hypoglycemia. Diabetes Care 14: 922-925

43. Patrick AW, Campbell IW (1990) Fatal hypoglycaemia in insulintreated diabetes mellitus: clinical features and neuropathological changes. Diabetic Med 7:349-354

44. Kalimo H, Olsson Y (1980) Effects of severe hypoglycemia on the human brain. Acta Neurol Scandinav. 62: 345-356

45. Auer RN (1986) Progress review: hypoglycemic brain damage. Stroke 17: 699-708

46. Myers RE, Kahn KJ (1971) Insulin-induced hypoglycemia in the non-human primate. II. Long-term neuropathological consequences. In: Brierley JB, Meldrum BS (eds) Brain hypoxia. Spastics International Medical Publications, London, pp 195-206

47. Perlmuter LC, Hakami M, Hodgson-Harrington C et al. (1984) Decreased cognitive function in aging non-insulin-dependent diabetic patients. Am J Med 77: 1043-1048

48. Mooradian A, Perryman K, Fitten J et al. (1988) Cortical function in elderly non-insulin-dependent diabetic patients. Arch Int Med 148: 2369-2372

49. Reaven G, Thompson L, Nahum D, Haskins E (1990) Relationship between hyperglycemia and cognitive function in older NIDDM patients. Diabetes Care 13: 16-21

50. U'Ren R, Riddle M, Lezak M, Bennington-Davis M (1990) The mental efficiency of the elderly person with type II diabetes mellitus. J Am Geriatric Soc 38: 505-510

51. Lawson J, Williams Erdahl D, Monga T et al. (1984) Neuropsychological function in diabetic patients with neuropathy. Br J Psych 145: 263-268

52. Harkins SW, Gardner DF, Anderson RA (1985) Auditory and somatosensory far-field evoked potentials in diabetes mellitus. Int J Neurosci 28: 41-47

53. Donald MW, Bird CE, Lawson JS, Letemendia FJJ (1981) Delayed auditory brainstem responses in diabetes mellitus. J Neur Neurosurg Psych 44: 641-644

54. Martini A, Comacchio F, Magnavita V (1991) Auditory brainstem and middle latency evoked responses in the clinical evaluation of diabetes. Diabetic Med 8 [Suppl]: S74-S77

55. Khardori R, Soler NG, Good DC, DevlescHoward AM, Broughton D, Walbert J (1986) Brainstem auditory and visual evoked potentials in type 1 (insulin-dependent) diabetic patients. Diabetologia 29: 362-365

56. Frier BM, Hilsted J (1985) Does hypoglycaemia aggravate the complications of diabetes? Lancet II: 1175-1177

Received: 3 August 1992 and in revised form: 26 November 1992

Dr. C.M. Ryan

Western Psychiatric Institute and Clinic

3811 O'Hara Street

Pittsburgh, PA 15213

USA 